University of Nebraska - Lincoln

DigitalCommons@University of Nebraska - Lincoln

Faculty Publications, Department of Psychology

Psychology, Department of

August 2005

\title{
Adolescent dating experiences described by Latino college students
}

Marcela Raffaelli

University of Nebraska-Lincoln, mraffaelli1@unl.edu

Follow this and additional works at: https://digitalcommons.unl.edu/psychfacpub

Part of the Psychiatry and Psychology Commons

Raffaelli, Marcela, "Adolescent dating experiences described by Latino college students" (2005). Faculty Publications, Department of Psychology. 317.

https://digitalcommons.unl.edu/psychfacpub/317

This Article is brought to you for free and open access by the Psychology, Department of at DigitalCommons@University of Nebraska - Lincoln. It has been accepted for inclusion in Faculty Publications, Department of Psychology by an authorized administrator of DigitalCommons@University of Nebraska - Lincoln. 
Published in Journal of Adolescence 28:4 (August 2005), pp. 559-572; doi 10.1016/j.adolescence.2005.04.001

Copyright (C) 2005 The Association for Professionals in Services for Adolescents Published by Elsevier Ltd. Used by permission. http://www.sciencedirect.com/science/journal/01401971

Published online May 23, 2005.

\title{
Adolescent dating experiences described by Latino college students
}

\author{
Marcela Raffaelli \\ Department of Psychology and Institute for Ethnic Studies, University of Nebraska-Lincoln, \\ Lincoln, NE 68588-0308; Tel. 402 472-0737; fax 402 472-4637.
}

\begin{abstract}
Latino college students $(\mathrm{M}$ age $=21.4$ years $)$ completed self-report surveys assessing adolescent dating experiences. Compared to young men $(n=69)$, young women $(n=$ 97) had more limitations placed on them by parents as adolescents and began dating later. No gender difference in timing of the first serious relationship emerged. More young women had their first relationship with a Latino, and having a Latino boyfriend was associated with older partner age. In multivariate analyses, parental level of education was a stronger correlate of early dating experiences than generational status, and stronger findings emerged for young women than young men. The findings highlight the salience of gender as an organizer of early dating experiences among Latino adolescents.
\end{abstract}

Keywords: dating, adolescent, latino/a

\section{Introduction}

The last century has seen a fundamental shift in how children and adolescents are socialized into adult roles related to sexuality and relationships. In modern societies like the US, individuals are expected to learn to negotiate sexuality without the external restraints that characterize tradi- 
tional cultures, such as gender segregation or arranged marriages (Brooks-Gunn \& Paikoff, 1997). As a result, adolescence is now considered a significant period for exploring relationships and sexuality (Miller \& Benson, 1999) and the majority of adolescents report dating ("going out" or "being with" someone) during the middle teen years. For example, in one study of White, middle class 15 -year-old girls, only $12 \%$ said they had never dated (Feiring, 1996). In a large-scale study, $73 \%$ of adolescents (mean age 14.8) had been on a date (Longmore, Manning, \& Giordano, 2001). There is typically a progression from casual to serious involvement (Miller \& Benson, 1999) such that by the end of the teen years, most youth have been involved in what they consider a serious relationship. In a national survey of in-school adolescents, the proportion reporting a "serious romantic relationship" in the last 18 months increased from one third of 13-year-olds to over half of 15-year-olds and 70\% of 17-year-olds (unpublished analysis of Add Health public use Wave I data). These studies suggest it is normative for US teenagers to experiment with romantic relationships during adolescence.

Adolescent romantic relationships have only relatively recently been the focus of attention by developmental scholars (e.g. Furman \& Wehner, 1997; Brown, Feiring, \& Furman, 1999). During the last two decades, theoretical views of adolescent romantic relationships have evolved and it is now accepted that these early relationships provide important developmental opportunities (e.g. Shulman \& Collins, 1997). At the same time, dealing with a teenager's forays into romance and sexuality is difficult for many parents (Zani, 1993; Gray \& Steinberg, 1999). Parents whose expectations and values differ from those of the majority culture may have an especially challenging time as their children become adolescents. Indeed, sexuality has been recognized as a focal point of familial tension among ethnic minority and immigrant families, whose expectations often conflict with US norms regarding adolescent romantic interest and activity (e.g. Espin, 1984/1997; Barkley \& Mosher, 1995). Despite the salience of adolescent sexuality for these families (and by extension for researchers, educators, and clinicians), little is known about normative patterns of dating and romance among ethnically diverse youth because most research on adolescent romantic relationships has been conducted with primarily European-American samples (e.g. Montemayor \& Gregg, 1994; Brown, 1999; Coates, 1999; Gray \& Steinberg, 1999). To begin filling this gap, the current analysis examined adolescent dating experiences retrospectively reported by Latino young adults.

There are two major reasons that Latinos (individuals of Latin American origin or descent living in the US) represent an important group in which to examine adolescent romantic relationships. First, it is estimated that by the year 2050, nearly one third of the under-19 population in the United States will be Latino (US Department of Health and Human Services, 2001). Therefore, understanding the experiences of Latino youth and their families will become increasingly important for developmental theorists, researchers, and practitioners (Parke \& Buriel, 1997). Second, despite encouraging declines in pregnancy rates among the general population of US adolescents, Latina adolescents are disproportionately likely to become pregnant and bear children (National Campaign to Prevent Teen Pregnancy, 2001). Because sexual exploration typically occurs in the context of romantic relationships (Miller \& Benson, 1999), gaining a fuller understanding of Latino adolescent relationships will ultimately inform intervention efforts.

Considering the relatively large amount of information available on normative patterns of dating and romantic involvement among "mainstream" adolescents, it is surprising how little is known about this aspect of Latino adolescents' lives. Based on traditional views of family and 
gender roles in Latino/Hispanic culture, scholars have proposed that parental acceptance of USstyle dating will depend on the gender of their child. The majority of scholars concur that there is a "double standard" for sexual behavior in most Latin cultures (for a review, see Raffaelli \& Suarez-al-Adam, 1998). For example, Espin (1984/1997) discussed how historical, religious and cultural influences led to a high value for female chastity as a marker for the family's honor. In contrast, because virility is an important component of male gender role expectations, young Latino men have typically experienced considerable freedom to explore their sexuality (e.g. Marín \& Gómez, 1997; Flores, Eyre, \& Millstein, 1998). Traditional notions about sexuality often conflict with what is considered normative in the larger US culture, and issues surrounding sexuality may become a central concern for Latino parents (Espin, 1984/1997). Indeed, Barkley and Mosher (1995) vividly described the difficulties some Hispanic families have as they negotiate the "mine fields of developing sexuality" (pp. 255-256).

Prior research with Latino adolescents supports the notion that parents are cautious regarding their daughters' sexuality. In a study of 10-15-year-old Puerto Rican and Mexican girls and their mothers, Villaruel (1998) described strategies families used to protect daughters from premature sexual involvement. These include prohibiting dating or imposing stringent rules regarding dating and contact with males (see also Raffaelli \& Ontai, 2001). Similarly, Taylor (1996) described mother-daughter relationships in a Latino and Portuguese sample as "bounded and defined by rules about gender roles and sexuality, rules that the girls both resist and find protective" (p. 126). An ethnographic study of 32 pregnant or parenting Mexican American adolescent girls revealed low levels of experience with males despite their sexual involvement (de Anda, Becerra, \& Fielder, 1990). Research also confirms that daughters are treated differently than sons. In a quantitative study of 14-16-year-old Latino and Anglo girls and boys, Latinas reported the strictest family rules about "dating, sex, and drugs" (Hovell et al., 1994). When asked about limitations placed on them as compared to opposite-sex siblings or relatives while growing up, Latino college students reported the greatest differential treatment in the area of curfews and interacting with members of the other sex (Raffaelli \& Ontai-Grzebik, 2004). These studies suggest that Latino male and female adolescents have different experiences linked to dating and romance; however, there is little systematic research on this aspect of Latino adolescents' lives.

Given the lack of developmental research on adolescent dating experiences among Latinos, the aim of the current analysis is primarily descriptive. This paper draws on a larger program of research on sexual socialization in Latino families. In an initial exploratory study, adult Latinas described family of origin experiences that often limited the degree to which they could engage in romantic exploration as adolescents (Raffaelli \& Ontai, 2001). Parents used a variety of tactics to limit and monitor adolescent daughters' romantic involvement; these included prohibiting dating before a certain age, curtailing opportunities for one-on-one interaction (e.g. only allowing daughters to spend time with boys in public or limiting boyfriends' access to the house), and not allowing daughters to date individuals from other ethnic groups, whose values would presumably be different. Moreover, respondents said they were treated very differently than their brothers, who were granted considerable freedom. In order to explore these findings more systematically, a follow-up study was conducted in which structured surveys were mailed to male and female Latino college students. The current paper examines retrospective reports of adolescent dating experiences in the college student sample. 
It should be noted from the outset that this sample is not representative of the general population of Latinos in the US In 1996, 57.5\% of 18-24-year-old Hispanics had completed high school, and about a third of high school graduates attended college (Wilds \& Wilson, 1998); therefore, a college sample represents a select group and family experiences may not be typical. Moreover, half of the respondents were born in the Midwestern state where the study was conducted. Nebraska is predominantly (87.3\%) European American (US Census Bureau, 2002). As is typical of other Great Plains states, however, established Mexican American enclaves and recent settlements of Central and South Americans are sprinkled across the state (Rochín, 2000). The characteristics of the sample are fully described below, to permit appropriate contextualization of the study findings.

The goals of the current analysis were to:

(1) Describe how Latino families negotiate their sons' and daughters' initial forays into romantic and potential sexual encounters;

(2) Compare adolescent dating experiences reported by male and female Latino young adults;

(3) Explore potential linkages between demographic variables and adolescent dating experiences. Because Latinos differ from non-Latinos on a number of dimensions that are linked to parenting values and behavior (such as educational level), socialization practices may reflect demographic rather than "cultural" factors. In fact, Hovell et al. (1994) reported that their Anglo and Latino samples differed on maternal education and acculturation but did not examine how these demographic characteristics contributed to differences within the Latino sub-sample. Therefore, associations between dating experiences and demographic variables were examined. Generational status and parental level of education were selected because they represent salient aspects of the experiences of Latinos in the US. Generation of immigration is often used as an indicator of acculturation-the process of psychological and behavioral adaptation that occurs when two cultures come into contact (Marín \& Marín, 1991). Parental education was included because socioeconomic status is a powerful influence on parental values and beliefs related to gender (Baca Zinn, 1995).

\section{Methods}

\section{Participants and procedures}

The sample represents a subset of respondents in a study targeting 19-45-year-old Latino men and women attending four Midwestern post-secondary institutions (two state universities, one community college, and one private university). With the cooperation of each institution's registration office, survey packets and subsequent reminder postcards were sent to all currently enrolled students identified as Latino/Hispanic in registration records. Depending on the institution, respondents were either paid $\$ 15$ or received $\$ 10$ and were entered into a drawing for an additional bonus payment. To protect student privacy, survey packets were direct-mailed by each institution; the investigator was not supplied with identifying or demographic information. At three institutions it was not possible to restrict the mailing to students aged 19-45 so the mailing was sent to all currently enrolled Latino/Hispanic students who were asked to discard the survey if they were under 19 (under state law they are considered minors) or over 45. Thus, 
the exact number of eligible students is unknown. A total of 871 surveys were mailed; 26 were undeliverable or recipients informed the investigator that they were ineligible. Of the remaining 845 surveys, 242 (28.6\%) were returned. To limit sample heterogeneity and retrospective recall bias, the current analysis was limited to respondents aged 25 and under $(n=166 ; 69 \%$ of the sample).

The analysis sample consists of 97 women and 69 men aged 19-25 (M age $=21.4$ years). Most respondents were unmarried (92\%), reported their religious affiliation as Catholic (71\%), and had been born in the United States (84\%). Among the 138 US-born respondents, $61 \%$ were born in the state where the research was conducted; the remaining participants were from 21 different states, most frequently California $(9.4 \%)$, Texas $(5.8 \%)$, or Colorado $(5.1 \%)$. Parental birthplace included the US (66\% of mothers, of $61 \%$ fathers), Mexico (12\% mothers, $16 \%$ fathers), or a South American (15\% mothers, $16 \%$ fathers), Central American (3\% mothers, $4 \%$ fathers) or other (4\% mothers, 3\% fathers) country. When asked to select the ethnic term(s) that best described them, 39\% of respondents $(n=65)$ chose "Hispanic/Latino," 34\% $(n=57)$ chose "Mexican-American" and the remainder selected "Mexican" (8\%; $n=13)$, "Puerto Rican" (4\%; $n=7)$, or another term (e.g. Chicano, Cuban, Latin American; $14 \% ; n=24)$.

\section{Measures}

As part of the larger study, participants completed a survey that included the following measures:

\section{Demographic variables}

Items indexing the birthplace of participants, parents, and grandparents were used to derive a continuous measure of generational status reflecting the number born in the US (Umaña-Taylor \& Fine, 2001). Possible scores ranged from 0 (no one born in the US) to 7 (self, both parents, and all four grandparents born in the US); $M=3.78$, s.d. $=2.40$. The average number of years of education completed was 12.8 for mothers (range 2-17) and 13.0 for fathers (range 0-17). These two items were correlated $(r=.64, p<.001)$, so a parent education composite was computed by averaging $(\mathrm{M}=12.9$, s.d. $=3.14)$. Generational status was not significantly associated with parent education $(r=.12, p>.12)$. Preliminary analyses revealed no gender differences in these demographic variables.

\section{Family rules and values regarding dating}

Based on pilot findings (Raffaelli \& Ontai, 2001) and other research (Villaruel, 1998), a set of questions to assess strategies parents used to manage their adolescent's emerging sexuality was created. Age limits to dating was examined with a single question ("Was there a certain age before which your parents felt you should not go on dates?") and affirmative responses were followed up with the question "What was that age?" Parental ethnic preference for dating partners was assessed with two items ("This parent told me I could only date people of the same ethnic group as our family"; "This parent told me it would be better if I dated people of the same ethnic group as our family") rated on a 5-point scale from "disagree strongly" to "agree strongly." The two items were rated for each parent, yielding four items that formed an acceptable scale $(\alpha=.88)$; all four items were averaged to create a composite. Finally, opportunities for one-on-one interaction 
Table 1. Opportunities for one-on-one interaction with boy/girlfriends during adolescence

\begin{tabular}{lrr}
\hline & Men & Women \\
\hline Romantic partners allowed in respondent's house? & & \\
No & $7.5 \%$ & $11.2 \%$ \\
Only if one or both parents were present & $23.9 \%$ & $23.6 \%$ \\
As long as another family member was at home & $20.9 \%$ & $40.4 \%$ \\
Unrestricted access to the house (even if alone) & $47.8 \%$ & $24.7 \%$ \\
Respondents allowed in romantic partner's house? & & \\
No & $1.5 \%$ & $18.9 \%$ \\
Only if one or both parents were present & $23.9 \%$ & $31.3 \%$ \\
As long as another family member was at home & $20.9 \%$ & $22.2 \%$ \\
Unrestricted access to the house (even if alone) & $53.7 \%$ & $2.68 / .94$ \\
Composite measure $(M / S D)$ & $3.18 / .82$ & \\
\hline
\end{tabular}

$N=65$ young men and 90 young women reporting a serious romantic relationship during adolescence $(93.4 \%$ of sample).

were assessed with two questions, one asking whether respondents' first boy/girlfriend had been allowed to come to their house and the other asking if they were allowed to go to the boy/girlfriend's house. A 4-point response scale was used indicating progressively lessening of restrictions (see Table 1 for response categories).

\section{Dating and romantic experiences}

Several aspects of early romantic experiences were examined, reflecting the typical progression of dating relationships (Zani, 1993) and experiences reported by pilot study participants. Ages of onset of dating (group, double, chaperoned, and unsupervised), first "serious or 'steady' relationship" and first voluntary sexual intercourse were assessed with open-ended items where respondents wrote in the age at which each type of activity first occurred.

\section{Romantic partner characteristics}

Age and ethnicity of the first romantic partner was assessed, and a variable indexing the age difference between the respondent and the first partner computed by subtracting the partner's age from the respondent's age.

\section{Results}

\section{Family rules and values}

The first set of analyses examined respondents' perceptions of parental values regarding dating and the kinds of restrictions parents established. 
Age limits to dating

When asked whether there was an age before which their parents did not want them to date, young women $(74 \%)$ were more likely than young men $(41 \%)$ to respond in the affirmative, $\chi^{2}$ $(1, N=166)=17.68, p<.0001$. Among the subset responding in the affirmative, no gender differences in the minimum age set by parents emerged (male $\mathrm{M}=15.7$ years, s.d. $=3.12$; female $\mathrm{M}=$ 15.9 years, s.d. $=1.42$ ).

\section{Parental ethnic preferences}

Respondents reported that their parents did not show a preference for same ethnic group partners (the mean score was between "disagree strongly" and "disagree slightly" that parents encouraged same ethnic group partners). No gender differences were found on this measure (male $\mathrm{M}=1.64$, s.d. =1.0; female $\mathrm{M}=1.69$, s.d. =1.1).

\section{Opportunities for one-on-one interaction}

Among the subset of respondents who were involved in a serious romantic relationship during adolescence (93\% of the sample), young men reported fewer restrictions than young women both in whether romantic partners were allowed to come over to their house, $\chi^{2}(3, N=156)=$ $10.99, p<.015$, and in whether they were allowed to go to a partner's house, $\chi^{2}(3, N=157)=$ $17.54, p<.001$ (see Table 1). For example, when asked whether their parents had restricted their romantic partners' access to the house, nearly half of the male respondents said their parents imposed no restrictions, compared to one quarter of the female respondents. Moreover, nearly one fifth of the female respondents said they were not allowed to go their boyfriend's house, even with parents or other family members present; in contrast, just one young man said he could not go to his girlfriend's house.

Because the two items assessing opportunities for one-on-one interaction were correlated $(r$ $=.62, p<.001)$, a composite measure for use in predictive analyses was created by averaging the items $(M=2.89$, s.d. $=.92)$. Descriptive statistics for the composite are shown at the bottom of Table 1; the average score for young men was significantly higher than the average for young women, reflecting greater opportunities for interactions with romantic partners, $t(2, N=155)=$ $3.48, p<.001$.

\section{Adolescent dating experiences}

The second goal of the study was to compare adolescent dating experiences reported by male and female Latino young adults. Two aspects of dating experiences were explored: initiation of different types of dating and romantic activities, and characteristics of the first romantic partner.

\section{Initiation of dating and romantic activities}

As shown in Table 2, young women reported that they started going on group, double, and unsupervised (couples) dates an average of half a year later than young men. However, young men and women became involved in a serious or "steady" relationship at the same age. For descriptive purposes, the proportion of respondents reporting specific relationship experiences by age 15 was also computed (chaperoned dating is not included because of the low number of re- 
Table 2. Adolescent romantic and dating experiences

\begin{tabular}{lcl}
\hline & Males & Females \\
\hline Age began going on group dates & 14.1 & $14.7^{*}$ \\
Age began going on chaperoned dates $^{\mathrm{a}}$ & 14.3 & 14.9 \\
Age began going on double dates $^{*}$ & 15.2 & $15.7^{*}$ \\
Age began going on unsupervised dates $^{\text {Age at first serious relationship }}{ }^{\mathrm{b}}$ & 15.9 & $16.4^{*}$ \\
Age of first voluntary sexual intercourse $^{\mathrm{c}}$ & 16.6 & 16.5 \\
Characteristics of first serious romantic partner $^{\mathrm{b}}$ & 16.2 & $17.0^{+}$ \\
Age of first romantic partner (years) $^{\text {Age difference (years) }}$ & 16.5 & $17.8^{* *}$ \\
Latino partner (\% yes) & -.09 & $1.36^{* * *}$ \\
\hline
\end{tabular}

$N=69$ young men, 97 young women unless otherwise indicated.

Significant gender differences: ${ }^{+} p<.10,{ }^{*} p<.05,{ }^{* *} p<.01,{ }^{* * *} p<.001$.

a Subset of respondents who reported going on dates chaperoned by a sibling or another relative; $n=21$ males, 39 females ( $36 \%$ of sample).

b Subset of respondents reporting a serious romantic relationship; $n=65$ males, 90 females ( $93.4 \%$ of sample).

c Subset of respondents reporting voluntary sexual intercourse; $n=50$ males, 69 females ( $72 \%$ of sample).

spondents reporting this form of dating). No gender differences emerged in the proportion of respondents initiating group $(62.3 \%$ of young men, $58.8 \%$ of young women) or double $(36.2 \%$ vs. $36.1 \%$ ) dating by age 15 . In contrast, unsupervised (couples) dating by age 15 was reported by more young men $(29.0 \%)$ than young women $(19.6 \%)$.

Among the subset of respondents who had experienced voluntary sexual intercourse, there was a trend $(p<.075)$ for young men to report an earlier age at first intercourse than young women (Table 2). Young men's first sexual experience typically occurred at an earlier age than their first serious relationship; in contrast, young women had their first sexual experience at a later age than their first steady relationship.

\section{First romantic partner}

Characteristics of the first serious romantic partner are displayed at the bottom of Table 2 . Young men tended to become involved with someone who was about their age or a little younger, whereas young women tended to become involved with romantic partners who were at least 1 year older. More descriptively, $9.2 \%$ of the young men reported that their first romantic partner was 2 or more years younger, whereas $20 \%$ of the young women said their first partner was 2 or 3 years older, and $11.1 \%$ had a first boyfriend who was $4-10$ years older.

This apparent inconsistency may reflect a tendency for young men and women to date partners from different ethnic groups. Just under a fifth of male respondents reported that their first serious romantic partner was Latina; in contrast, nearly two fifths of the female respondents said their first partner was Latino (Table 2). The majority of young men became involved with a European-American $(76.5 \%)$ or someone from another ethnic group $(4.4 \%)$. In comparison, under half the young women reported that their first romantic partner was European-American (48.4\%), and $14 \%$ dated someone from another ethnic group. This difference was significant, $\chi^{2}(2, N=159)=$ $13.25, p<.0015$. 
Follow-up analyses (not shown) revealed that for young women only, partner ethnicity and age difference between self and partner were associated. The mean age difference for women with Latino partners $(n=33)$ was significantly higher $(\mathrm{M}=2.03$, s.d. $=2.70)$ than that for women with non-Latino partners $(n=57)(\mathrm{M}=0.96$, s.d. $=1.73) ; t(1, N=47)=2.04, p<.05$. More descriptively, in over two fifths $(45.5 \%)$ of cases where the male partner was Latino, the age differences between partners was at least 2 years; in contrast, just over a fifth $(22.7 \%)$ of women with a nonLatino partner reported an age disparity of 2 years or more.

\section{Correlates of early dating experiences}

The third goal was to explore potential linkages between demographic variables and adolescent dating experiences. To accomplish this goal, regressions models were computed in which generational status and parental education were entered simultaneously into models predicting different aspects of dating experiences. Linear regressions were computed to predict continuous outcomes (parental ethnic preferences, composite measures reflecting opportunities for one-onone interactions, age at onset of group and couples dating, age at first serious relationship, age difference between self and partner). Logistic regressions were computed to predict dichotomous outcomes (whether parents set age limits to dating, partner ethnicity). Age of onset of group dating and double dating were highly correlated for both young men $(r=.79, p<.001)$ and women $(r$ $=.67, p<.001$ ); therefore, only group dating (the earliest form of dating) was evaluated in the predictive analyses. Separate equations were computed by gender.

Results of the linear and logistic regressions are shown in Table 3. Two of the eight models reached statistical significance $(p<.05)$ for male respondents; in contrast, five of the models for female respondents were significant. Thus, it appears that the demographic predictors evaluated were more salient for adolescent girls' dating experiences than they were for boys'.

For young men, the model for parental ethnic preferences was significant, with parent education independently predicting weaker preferences for sons to date same ethnic group partners.

Table 3. Regression models predicting adolescent dating experiences from generational status and parent education

\begin{tabular}{lcclllll}
\hline & \multicolumn{3}{c}{ Young men $(n=69)$} & \multicolumn{2}{c}{ Young women $(n=97)$} \\
& Generation & Par educ & Model statistics & Generation & Par educ & Model statistics \\
\hline Linear regressions & & & & & & & \\
Parental ethnic preference & -.06 & $-.35^{* *}$ & $R^{2}=.13, F=4.78^{*}$ & -.07 & $-.22^{*}$ & $R^{2}=.06, F=2.68^{+}$ \\
One-on-one interaction & .03 & .17 & $R^{2}=.03, F=.97$ & $.23^{*}$ & $.45^{* * *}$ & $R^{2}=.26, F=15.49^{* * *}$ \\
Age began group dating & .14 & $-.32^{*}$ & $R^{2}=.10, F=3.01^{+}$ & $.21^{*}$ & $-.395^{* * *}$ & $R^{2}=.18, F=9.66^{* * *}$ \\
Age began couples dating & -.11 & -.04 & $R^{2}=.015, F=.49$ & .05 & $-.28^{* *}$ & $R^{2}=.08, F=3.69^{*}$ \\
Age first relationship & -.12 & .02 & $R^{2}=.015, F=.46$ & .08 & $-.23^{*}$ & $R^{2}=.05, F=2.51$ \\
Age difference 1st partner & -.06 & -.03 & $R^{2}=.01, F=.17$ & -.16 & -.12 & $R^{2}=.04, F=1.92$ \\
Logistic regressions & & & & & & \\
Parental age limit dating & -.01 & -.08 & $\chi^{2}=.92$ & -.13 & $.16^{+}$ & $\chi^{2}=6.05^{*}$ \\
Partner ethnicity & $.34^{*}$ & .01 & $\chi^{2}=6.43^{*}$ & $.29^{* *}$ & $.14^{+}$ & $\chi^{2}=13.11^{* *}$ \\
\hline
\end{tabular}

Note: Degrees of freedom $(\mathrm{df})=2$ for all models. $N$ 's may vary due to missing data for some variables. Figures are standardized regression coefficients. Significance levels: ${ }^{*} p<.075 ;{ }^{*} p<.05,{ }^{* *} p<.01,{ }^{* * *} p<.001$.

a Coded as 0 = yes, $1=$ no; ${ }^{b}$ coded as $0=$ Latino, $1=$ non-Latino. 
The model for partner ethnicity was also significant; young men with higher generational status were more likely to report that their first serious girlfriend was not Latina.

For young women, the model for ethnic preferences did not reach statistical significance, but a similar pattern to that found for young men emerged such that higher levels of parental education were associated with lower preferences for same ethnic group dating partners. In the model examining opportunities for one-on-one interactions with romantic partners, higher levels of both parental education and generational status were associated with greater freedom to interact with romantic partners in the respondent's or the partner's home. Models examining age of onset of group and couples dating were significant for young women, but not those examining age at first relationship or age difference between the respondent and her first romantic partner. Age of initiation of group dating was associated positively with generational status and negatively with parent education, and onset of couples dating was associated (negatively) with parent education, suggesting that parents with higher levels of education had daughters who began dating at earlier ages. The model examining whether parents had set an age limit for dating was significant, but neither of the predictors was significant (parent education was marginally significant). Finally, in the logistic regression for partner ethnicity, generational status (significantly) and parent education (marginally) predicted partner ethnicity such that higher generational status and parental education were associated with young women having their first relationship with a nonLatino romantic partner.

\section{Discussion}

This study's overall goal was to explore adolescent dating experiences among Latinos. Once largely ignored by developmental researchers, adolescent romantic relationships are now considered significant developmental contexts, and researchers have devoted a considerable amount of energy to exploring processes, influences, and outcomes of those relationships. At the same time, almost nothing is known about adolescent dating relationships among Latinos, who constitute the fastest growing segment of the US population (National Campaign, 2001).

Several key findings emerged from this analysis of adolescent dating experiences reported by Latino college students. Most notably, pervasive gender differences were reported in adolescent dating experiences. Consistent with prior research (e.g. Hovell et al., 1994), young women reported having more limitations placed on them during adolescence by parents than young men. Three quarters of female respondents said their parents did not want them to date before a specific age (nearly 16 years), and young women reported more restrictions on interactions with their romantic partners. Moreover, young women delayed involvement in early forms of dating (e.g. group and double dating); and initiated unsupervised "couples" dates about half a year later than young men. The fact that marked gender differences were seen in a highly educated, primarily non-immigrant sample of Latinos suggests that traditional values regarding appropriate behavior for girls and boys continue to exert an influence (Espin, 1984/1997; Marín and Gómez, 1997; Flores et al., 1998). Future research is needed to examine whether the same patterns are evident in samples of Latino adolescents who are actually in the process of initiating dating and romantic activities, and to evaluate the influence of parents' cultural values on attitudes towards their adolescent children's involvement in dating activities. 
Another noteworthy finding is that the early dating partners of Latino young men and women tended to differ in ethnicity and age gap between partners. Young women were more likely than young men to say their first romantic partner was Latino, and there was also a relatively large age difference between female respondents and their first serious romantic partner, particularly among those whose first boyfriend was Latino. Past research has reported that Latina adolescents are often involved with older partners (e.g. de Anda et al., 1990; Flores et al., 1998; Marín, Coyle, Gómez, Carvajal, \& Kirby, 2000). The current study suggests that this may be especially likely when both members of the couple are Latino, pointing to the need to obtain a more differentiated picture of adolescent romantic relationships.

Despite pervasive gender differences in most aspects of dating, young men and women experienced their first serious relationship at about the same age. As a result, there was a compression in Latinas' dating experiences; the lag between initiating unsupervised dating (16.4 years) and becoming involved in a serious romantic relationship (16.5 years) was much smaller than the lag for males (from 15.9 to 16.6 years). Taken as a whole, the findings provide some basis for speculation about why Latina adolescents in the US may be at elevated risk of teen pregnancy and nonmarital births (National Campaign, 2001). In modern societies, the adolescent years represent a crucial time "to practice managing sex and gender" (Thompson, 1994, p. 219). It may be that the combination of delayed dating onset and involvement with older partners puts some Latinas at a disadvantage as they enter a serious romantic relationship, offering clues as to why MexicanAmerican girls who have been pregnant can still be "remarkably inexperienced in relationships with males" (de Anda et al., 1990, p. 312). In nationally representative samples, involvement with older partners has been linked to early onset of sexual activity (Marín et al., 2000), ambivalence about sexual initiation (Abma, Driscoll, \& Moore, 1998) and an increased likelihood of teen pregnancy (Darroch, Landry, \& Oslak, 1999). The role of early dating experiences in magnifying Latina teens' risk of teenage pregnancy deserves further attention.

Gender differences in family rules and early experiences relating to dating are consistent with traditional cultural values regarding sexuality. However, it is noteworthy that parental education was a better predictor of early dating experiences than was generational status, given that family members' immigration history is often used as an indicator of acculturation (Phinney, 2003). Furthermore, there was no evidence of a parental preference for same ethnicity dating partners for adolescent children, perhaps reflecting the primarily European American contexts in which many respondents grew up. Instead, the general pattern of results suggested that parental education was associated with a "loosening" of restrictions regarding daughter's sociosexual activity. Among the eight aspects of early dating experiences examined in the current study, two models were significant for young men and five for young women, suggesting that parental demographic characteristics are more salient for females and that different factors may underlie dating onset among Latino males and females. Future research should more fully examine differences among Latino families in how they negotiate their sons' and daughters' adolescent dating experiences, with particular attention to the role of parent characteristics including demographic and cultural variables.

These findings shed light on the dating experiences of Latino adolescents, and suggest that gender is an important organizer of those experiences. However, this paper has several limitations that should be addressed in future research. First, as discussed earlier, the sample consisted of college and university students; therefore, the respondents are not representative of the gen- 
eral Latino population. However, the fact that significant gender differences emerged even in this sample suggests that the findings might be even stronger in a general sample of Latinos. A second limitation is the study's retrospective design. Retrospective reports are subject to forgetting and re-evaluation of past experiences, although scholars maintain that family of origin experiences can be assessed retrospectively (e.g. Melchert \& Sayger, 1998), and this methodology has been used to examine characteristics of Latino families (e.g. López \& Hamilton, 1997) and early dating experiences of European-American college students (Spreadbury, 1982). Finally, it was not possible to explore possible interactions among demographic factors (e.g. timing of immigration, national origin, socioeconomic status); future research should attempt to explicate how these variables operate together on adolescent dating experiences. Despite these limitations, this study yields novel information about early forays into dating and romantic relationships by Latino adolescents. It also provides a basis for future research investigating the dating experiences of culturally diverse adolescents.

\section{Acknowledgments}

This research was funded by grants to Marcela Raffaelli from the National Institute of Mental Health (RO3-MH57650) and by the University of Nebraska Research Council. The author thanks Jennifer Crispo, Shanta Griffin, Stephanie Green, Jennifer Haase, Stephanie Hewitt, Sarah Kepple, Lynn Marcus, Nicole Miller, Lenna Ontai, Tammy Pfeifer, Katie Pickett, Julie Siepker, Kathryn Wilke, and Byron Zamboanga for their research assistance. An earlier version of this paper was presented at Society for Research on Child Development (Minneapolis, April 2001).

\section{References}

Abma, Driscoll, \& Moore (1998): J. C. Abma, A. K. Driscoll, and K. A. Moore, Young women's degree of control over first intercourse: An exploratory analysis, Family Planning Perspectives 30 (1998), pp. 12-18.

Baca Zinn (1995): M. Baca Zinn, Social science theorizing for Latino families in the age of diversity. In: R. E. Zambrana, Editor, Understanding Latino families: Scholarship, policy, and practice, Sage, Thousand Oaks, CA (1995), pp. 177-189.

Barkley \& Mosher (1995): B. H. Barkley and E. S. Mosher, Sexuality and Hispanic culture: Counseling with children and their parents, Journal of Sex Education and Therapy 21 (1995), pp. 255-267.

Brooks-Gunn \& Paikoff (1997): J. Brooks-Gunn and R. Paikoff, Sexuality and developmental transitions during adolescence. In: J. Schulenberg, J. L. Maggs and K. Hurrelmann, Editors, Health risks and developmental transitions during adolescence, Cambridge University Press, Cambridge, UK (1997), pp. 190-219.

Brown (1999): B. B. Brown, "You're going out with who?" peer influences on adolescent romantic relationships. In: B. Brown, C. Feiring and W. Furman, Editors, The development of romantic relationships in adolescence, Cambridge University Press, New York, NY (1999), pp. 291-329.

Brown, Feiring, \& Furman (1999): B. B. Brown, C. Feiring, and W. Furman, Missing the love boat: Why researchers have shied away from adolescent romance. In: B. Brown, C. Feiring and W. Furman, Editors, The development of romantic relationships in adolescence, Cambridge University Press, New York (1999), pp. 1-16.

Coates (1999): D. L. Coates, The cultured and culturing aspects of romantic experience in adolescence. In: B. Brown, C. Feiring and W. Furman, Editors, The development of romantic relationships in adolescence, Cambridge University Press, New York (1999), pp. 330-363. 
Darroch, Landry, \& Oslak (1999): J. E. Darroch, D. J. Landry, and S. Oslak, Age differences between sexual partners in the United States, Family Planning Perspectives 31 (1999), pp. 160-167.

de Anda, Becerra, \& Fielder (1990): D. de Anda, R. M. Becerra, and E. Fielder, In their own words: The life experiences of Mexican-American and White pregnant adolescents and adolescent mothers, Child and Adolescent Social Work 7 (1990), pp. 301-318.

Espin (1984/1997): O. M. Espin, Cultural and historical influences on sexuality in Hispanic/Latin women: Implications for psychotherapy. In: O. M. Espin, Editor, Latina realities: Essays on healing, migration, and sexuality, Westview, Boulder, CO (1984/1997), pp. 83-96.

Feiring (1996): C. Feiring, Concepts of romance in 15-year-old adolescents, Journal of Research on Adolescence 6 (1996), pp. 181-200.

Flores, Eyre, \& Millstein (1998): E. Flores, S. Eyre, and S. G. Millstein, Sociocultural beliefs related to sex among Mexican American adolescents, Hispanic Journal of Behavioral Sciences 20 (1998), pp. 60-82.

Furman \& Wehner (1997): W. Furman and E. A. Wehner, Adolescent romantic relationships: A developmental perspective. In: S. Shulman and W. A. Collins, Editors, Romantic relationships in adolescence: Developmental perspectives, Jossey-Bass, San Francisco, CA (1997), pp. 21-36.

Gray \& Steinberg (1999): M. R. Gray and L. Steinberg, Adolescent romance and the parent-child relationship. In: B. Brown, C. Feiring and W. Furman, Editors, The development of romantic relationships in adolescence, Cambridge University Press, New York (1999), pp. 235-265.

Hovell et al. (1994): M. Hovell, C. Sipan, E. Blumberg, C. Atkins, C. R. Hofsteter and S. Kreitner, Family influences on Latino and Anglo adolescents' sexual behavior, Journal of Marriage and the Family 56 (1994), pp. 896-973.

Longmore, Manning, \& Giordano (2001): M. A. Longmore, W. D. Manning, and P. C. Giordano, Preadolescent parenting strategies and teen's dating and sexual initiation: A longitudinal analysis, Journal of Marriage and Family 63 (2001), pp. 322-335.

López \& Hamilton (1997): L. C. López and M. Hamilton, Comparison of the role of Mexican-American and EuroAmerican family members in the socialization of children, Psychological Reports 80 (1997), pp. 283-288.

Marín, Coyle, Gómez, Carvajal, \& Kirby (2000): B. V. Marín, K. K. Coyle, C. A. Gómez, S. C. Carvajal, and D. B. Kirby, Older boyfriends and girlfriends increase risk of sexual initiation in young adolescents, Journal of Adolescent Health 27 (2000), pp. 409-418.

Marín \& Gómez (1997): B. V. Marín and C. A. Gómez, Latino culture and sex: Implications for HIV prevention. In: J. Garcia and M. Zea, Editors, Psychological interventions and research with Latino populations, Allyn and Bacon Inc., Boston, MA (1997), pp. 73-93.

Marín \& Marín (1991): G. Marín and B. V. Marín, Research with Hispanic populations, Sage, Newbury Park, CA (1991).

Melchert \& Sayger (1998): T. P. Melchert and T. V. Sayger, The development of an instrument for measuring memories of family of origin characteristics, Educational and Psychological Measurement 58 (1998), pp. 99-118.

Miller \& Benson (1999): B. C. Miller and B. Benson, Romantic and sexual relationship development during adolescence. In: B. Brown, C. Feiring and W. Furman, Editors, The development of romantic relationships in adolescence, Cambridge University Press, New York (1999), pp. 99-121.

Montemayor \& Gregg (1994): R. Montemayor and V. R. Gregg, Current theory and research on personal relationships during adolescence. In: G. R. Adams, T. P. Gullotta and R. Montemayor, Editors, Personal relationships during adolescence, Sage, Thousand Oaks, CA (1994), pp. 236-245.

National Campaign Prevent Teen (2001): National Campaign to Prevent Teen Pregnancy. (2001). Fact sheet: Teen pregnancy and childbearing among Latinos in the United States. The National Campaign to Prevent Teen Pregnancy; http://www.teenpregnancy.org

Parke \& Buriel (1997): R. D. Parke and R. Buriel, Socialization in the family: Ethnic and ecological perspectives. In W. Damon, N. Eisenberg (Eds.), Handbook of child psychology, Vol. 3, Social, emotional, and personality development (5th ed. pp. 463-552). New York: Wiley. 
Phinney (2003): J. S. Phinney, Ethnic identity and acculturation. In: K. M. Chun, P. B. Organista and G. Marín, Editors, Acculturation: Advances in theory, measurement, and applied research, American Psychological Association, Washington, DC (2003), pp. 63-81.

Raffaelli \& Ontai (2001): M. Raffaelli and L. L. Ontai, “She's 16 years old and there's boys calling over to the house": An exploratory study of sexual socialization in Latino families, Culture, Health, and Sexuality 3 (2001), pp. 295-310.

Raffaelli \& Ontai-Grzebik (2004): M. Raffaelli and L. L. Ontai-Grzebik, Gender socialization in Latino/a families: Results from two retrospective studies, Sex Roles: A Journal of Research 50 (2004), pp. 287-299.

Raffaelli \& Suarez-al-Adam (1998): M. Raffaelli and M. Suarez-al-Adam, Reconsidering the HIV/AIDS prevention needs of Latino women in the United States. In: N. L. Roth and L. K. Fuller, Editors, Women and AIDS: Negotiating safer practices, care, and representation, Haworth, New York (1998), pp. 7-41.

Rochín (2000): R. I. Rochín, Latinos on the Great Plains: An overview, Great Plains Research 10 (2000), pp. $243-252$.

Shulman \& Collins (1997): S. Shulman and W. A. Collins, Editors' notes. In: S. Shulman and W. A. Collins, Editors, Romantic relationships in adolescence: Developmental perspectives, Jossey-Bass Inc., San Francisco, CA (1997), pp. 1-2.

Spreadbury (1982): C. L. Spreadbury, First date, Journal of Early Adolescence 2 (1982), pp. 83-89.

Taylor (1996): J. M. Taylor, Cultural stories: Latina and Portuguese daughters and mothers. In: B. J. R. Leadbeater and N. Way, Editors, Urban girls: Resisting sterotypes, creating identities, New York University Press, New York (1996), pp. 117-131.

Thompson (1994): S. Thompson, Changing lives, changing genres: Teenage girls' narratives about sex and romance, 1978-1986. In: A. S. Rossi, Editor, Sexuality across the life course, University of Chicago Press, Chicago (1994), pp. 209-232.

Umaña-Taylor \& Fine (2001): A. Umaña-Taylor and M. A. Fine, Methodological implications of grouping Latino adolescents into one collective ethnic group, Hispanic Journal of Behavioral Sciences 23 (2001), pp. 347-362.

US Census (2002): US Census Bureau. (2002). State Quick Facts (Nebraska). Retrieved on February 17, 2003 from http://quickfacts.census.gov/qfd/states/31000.html

US Department Health and Human (2001): US Department of Health and Human Services. (2001). Mental health: Culture, race and ethnicity-Supplement to mental health: A report of the Surgeon General. Rockville, MD.

Villaruel (1998): A. M. Villaruel, Cultural influences on the sexual attitudes, beliefs, and norms of young Latina adolescents, Journal of the Society of Pediatric Nurses 3 (1998), pp. 69-79.

Wilds \& Wilson (1998): D. J. Wilds and R. Wilson, Minorities in higher education 1997-1998, American Council on Education, Washington, DC (1998).

Zani (1993): B. Zani, Dating and interpersonal relationships in adolescence. In: S. Jackson and H. RodriguezTome, Editors, Adolescence and its social worlds, Wheatons, East Sussex, UK (1993), pp. 95-119. 